\title{
Predicting wind-driven rain catch ratios in building simulation using machine learning techniques
}

\author{
Ioanna Vrachimi, Daniel Cóstola \\ University of Strathclyde, Glasgow, United Kingdom
}

\begin{abstract}
Wind-driven rain catch-ratios are an important boundary condition for the study of the hygrothermal behaviour and durability of building envelopes. Measurements are time-consuming, expensive and of limited applicability to other facades of other buildings and sites. CFD simulations are accurate, but time consuming and simplified calculation have large uncertainty. This work focuses on improving the use of WDR catch-ratios in building simulation using artificial neural networks (ANNs). Results obtained indicate that an ANN can predict WDR catch-ratio with an uncertainty of \pm 0.07 for a confidence interval of $95 \%$. ANNs have the ability to combine results from multiple experiments/simulations to provide catchratios at any position at the façade and extrapolate them to a range of façade's aspect ratios.
\end{abstract}

\section{Introduction}

There is a strong integration between data driven models and building performance simulation in recent years (Amasyali and El-gohary (2018)). Historically, this has been done with regression analysis and the present work is part of a larger project that evaluates opportunities to use more comprehensive machine learning techniques to improve the quality of data driven models in building performance simulation. Previous instances of this work were on wind pressure coefficient for isolated and non-isolated low-rise buildings (Vrachimi et al. (2017)). This one is expanding this work in direction of other phenomena, in this case wind driven rain (WDR), while other phenomena will be addressed by the project at later stages (e.g. convective heat and mass transfer coefficients, sky temperature models). Indoor air quality and occupant's perception of it largely depends on indoor humidity. Thus, in the building physics area, moisture-associated problems have become an important subject. Numerical heatair-moisture (HAM) transfer models are increasingly being used to study the hygrothermal performance of building facades. Accurate HAM-transfer analyses require adequate boundary conditions. Typically,

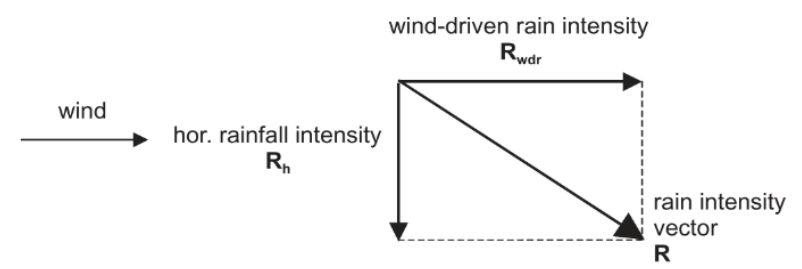

Figure 1: Rain intensity vector $R$ and its components: Wind-driven rain intensity $R_{w} d r$ and horizontal rainfall intensity $R_{h}$ (Blocken and Carmeliet (2004)).

the input of HAM models comprises of a standard meteorological data record (containing air temperature, relative humidity, solar radiation, cloud factor, reference wind speed, wind direction and horizontal rainfall intensity) from which the specific boundary conditions are calculated. Although most boundary conditions can be quite adequately described for HAM-transfer analysis, there is at least one that is still considered to be problematic: wind driven rain (Blocken and Carmeliet (2007)).

WDR is considered to be one of the most important moisture sources affecting building envelopes and during the last twenty years, research has been conducted around this. The aim of those studies lies in the evaluation of one parameter, the catch ratio, which links the unobstructed horizontal rainfall intensity to the WDR intensity on the building as shown in Figure 1 (Blocken and Carmeliet (2004)) and defined in equation 1 .

$$
\eta_{d}(d, t)=\frac{R_{w d r}(d, t)}{R_{h}(d, t)}, \eta(t)=\frac{R_{w d r}(t)}{R_{h}}
$$

$R_{w d r}(d, t)$ and $R_{h}(d, t)$ are the specific WDR intensity and specific unobstructed horizontal rainfall intensity for raindrops with diameter $d$. $R_{w d r}(t)$ and $R_{h}(t)$ respectively, refer to the same quantities but integrated over all raindrop diameters. Specific catch ratio is related to only one droplet size whereas catch ratio is the whole spectrum of droplet sizes (Best (1950)).

This WDR catch ratio can be evaluated with on-site measurements, semi-empirical models and numerical simulations. Measurements are expensive and they considerably take more time than semi-empirical 
models. Secondary sources are largely used to obtain WDR catch-ratio as they are inexpensive and straightforward. The most widely used models are the Straube and Burnett (S\&B) model (Straube and Burnett (2000)), ISO Standard (ISO (2009)) and the Computational Fluid Dynamics (CFD) model by Choi (1993) further developed by Blocken and Carmeliet (2002); Blocken et al. (2007). ISO Standard and S\&B model are defined by equations 2 and 3 respectively, below.

$$
\begin{gathered}
R_{w d r}=\frac{2}{9} C_{R} C_{T} O W U_{10} R_{h}^{0.88} \cos \theta \\
R_{w d r}=D R F \times R A F \times U_{(z)} \times R_{h} \times \cos \theta
\end{gathered}
$$

where $C_{R}$ is the roughness coefficient, $C_{T}$ is the topography coefficient, $O$ is the obstruction factor, $W$ is the wall factor, $U_{10}$ is the reference wind speed at $10 \mathrm{~m}$ height in the upstream undisturbed flow $(\mathrm{m} / \mathrm{s}), R_{h}^{0.88}$ is the horizontal rainfall intensity $\left(\mathrm{mm} / \mathrm{h}\right.$ or $\left.L / \mathrm{m}^{2}\right)$ and $\theta$ is the angle between the wind direction and the normal to the façade. For equation $3, \mathrm{DRF}$ is the driving rain function, $\mathrm{RAF}$ is the rain admittance factor, $U(z)$ is the mean wind velocity vector $(\mathrm{m} / \mathrm{s}), R h$ is the horizontal rainfall intensity $\left(\mathrm{mm} / \mathrm{hor} L / \mathrm{m}^{2}\right)$ and $\theta$ is the same as the previous equation. Both models have been described and compared in detail by Blocken and Carmeliet (2010).

A comparison of the two semi-empirical models shows that the S\&B model provides information for three building façade geometries whereas the ISO Standard model provides for six. A relatively low number for both models considering the number of different façade geometries that can exist. The S\&B model though brings up the independence of building and scale for RAF values. Regarding the two models and the position on the façade they have two different approaches. The ISO Standard model provides wall factors (W) across different points on façade, but no more than nine for a three-storey building. On the other hand, the S\&B model provides contour graphs with maximum and minimum RAF values. Although the two parameters define the same thing, the ratio of the WDR intensity on the façade to the free-field WDR intensity, they don't share the same values at some façade positions (Blocken and Carmeliet (2010)). The use of considerably simplified WDR intensity and therefore WDR catch-ratio has major limitations and may incur in high error in the hygrothermal behaviour of building facades (Abuku et al. (2009)).

Artificial Neural Networks (ANNs) have shown successful results in a variety of fields, such as banking (Tavana et al. (2017)), ocean engineering (Seyedashraf et al. (2017)), microelectronics (Khera and Khan (2017)), human science (Aram et al. (2017)), agriculture (Elnesr and Alazba (2017)), thermal comfort (von Grabe (2016)) and particularly on applications related to building performance and physics (Deb et al. (2016); Kumar et al. (2013); Magalhães et al. (2017); Melo et al. (2014)). The same approach will be used for this work as well. In terms of WDR catch ratio data, available data at the Heat Air Moisture Finite Element Method (HAMFEM) program (Janssen (2000)) and data from a CFD simulation (Choi (1994)) will be used. The user has to manually choose the façade in the database with the closest aspect ratio to the façade under analysis, as the linear interpolation algorithm has no means to extrapolate results for new façade aspect ratios from the existing datasets. This was one of the first attempts to implement CFD simulation results in heat-air-moisture (HAM) software (Blocken et al. (2007)). Based on the above, the present paper describes an investigation on modelling WDR catch ratios using ANN and the reference data from HAMFEM and CFD simulations.

\section{Methodology}

This section describes the reference data from CFD simulations and HAMFEM program used in the analysis, the use of the data in the quantification of the uncertainty in ISO Standard and S\&B model and the development of ANN to calculate WDR catch ratio based on the reference data.

\section{Reference data}

This work relies on two datasets both originally developed using CFD simulations. The first dataset is provided by HAMFEM program (Janssen (2000)), originally developed by Blocken and Carmeliet (2007) and the second one on data from Choi (1994).

Table 1: Catch ratios for various horizontal rainfall intensities as obtained by (Choi (1994)).

\begin{tabular}{|c|c|c|c|c|c|c|c|c|c|}
\hline \multirow{2}{*}{$\begin{array}{c}\mathbf{R}_{\mathbf{h}} \\
(\mathbf{m m} / \mathbf{h})\end{array}$} & \multicolumn{3}{|c|}{$\begin{array}{c}\text { Wind Speed } \\
\mathbf{1 0} \mathbf{~ m} / \mathbf{s}\end{array}$} & \multicolumn{3}{c|}{$\begin{array}{c}\text { Wind Speed } \\
\mathbf{2 0} \mathbf{~ m} / \mathbf{s}\end{array}$} & \multicolumn{3}{c|}{$\begin{array}{c}\text { Wind Speed } \\
\mathbf{3 0} \mathbf{~ m} / \mathbf{s}\end{array}$} \\
\cline { 2 - 10 } & $\mathbf{1 0}$ & $\mathbf{3 0}$ & $\mathbf{5 0}$ & $\mathbf{1 0}$ & $\mathbf{3 0}$ & $\mathbf{5 0}$ & $\mathbf{1 0}$ & $\mathbf{3 0}$ & $\mathbf{5 0}$ \\
\hline $\mathbf{S 4}$ & 0.46 & 0.47 & 0.47 & 1.19 & 1.18 & 1.17 & 2.37 & 2.21 & 2.15 \\
\hline $\mathbf{S 3}$ & 0.19 & 0.22 & 0.23 & 0.87 & 0.86 & 0.86 & 1.90 & 1.80 & 1.76 \\
\hline $\mathbf{S 2}$ & 0.13 & 0.15 & 0.16 & 0.72 & 0.73 & 0.73 & 1.69 & 1.62 & 1.60 \\
\hline $\mathbf{S 1}$ & 0.09 & 0.11 & 0.11 & 0.47 & 0.50 & 0.51 & 1.43 & 1.40 & 1.39 \\
\hline $\mathbf{C 4}$ & 0.41 & 0.43 & 0.44 & 1.23 & 1.18 & 1.16 & 2.20 & 2.08 & 2.03 \\
\hline $\mathbf{C 3}$ & 0.14 & 0.18 & 0.19 & 0.74 & 0.77 & 0.77 & 1.78 & 1.70 & 1.67 \\
\hline $\mathbf{C 2}$ & 0.08 & 0.11 & 0.12 & 0.61 & 0.64 & 0.65 & 1.58 & 1.53 & 1.51 \\
\hline $\mathbf{C 1}$ & 0.05 & 0.07 & 0.08 & 0.34 & 0.40 & 0.43 & 1.31 & 1.30 & 1.30 \\
\hline
\end{tabular}

Table 1 shows the catch ratios as obtained by (Choi (1994)), referred as Choi data hereafter, for a building with cross section $10 \mathrm{~m}$ by $10 \mathrm{~m}$ and height $40 \mathrm{~m}$. As shown in Figure 2(a) the building façade was divided into 12 large areas with vertical side strips named $\mathrm{S}$ and the centre strip name $\mathrm{C}$. The wind flow pattern was calculated for reference wind speed values of 10 , 20 and $30 \mathrm{~m} / \mathrm{s}$, at $250 \mathrm{~m}$ height, and horizontal rainfall intensities of 10,30 and $50(\mathrm{~mm} / \mathrm{h})$. HAMFEM dataset was originally developed using CFD simulations and shows catch ratio data at the local position 
of analysis on the façade. The model available from HAMFEM program as shown in Figure 2(b) shows a building with $10 \mathrm{~m}$ height with the same cross section area as the previous model, i.e. $10 \mathrm{~m}$ by $10 \mathrm{~m}$. The reference data has been tested for 9 wind speeds (from $0 \mathrm{~m} / \mathrm{s}$ up to $10 \mathrm{~m} / \mathrm{s}$ ) and for 16 horizontal rain fall intensities (from $0 \mathrm{~mm} / \mathrm{h}$ to $30 \mathrm{~mm} / \mathrm{h}$ ) resulting in a total of 4861 entries from both data. Table 2 shows sample data available from HAMFEM and Figure 3 shows the cubic sized model's facade which was divided into 40 areas. Assuming that both, the building and the flow are symmetrical, 9 areas named from A to I as shown in Figure 3, have been chosen from one side of the cube as sample data to be presented in Table 2. Training and validation of ANN has been done using the above data.

Table 2: Sample data of catch ratios from HAMFEM dataset for various horizontal rainfall intensities as obtained by (Blocken et al. (2007)).

\begin{tabular}{|c|c|c|c|c|c|c|c|c|c|}
\hline \multirow{2}{*}{$\begin{array}{c}\mathbf{R}_{\mathrm{h}} \\
(\mathrm{mm} / \mathbf{h})\end{array}$} & \multicolumn{3}{|c|}{$\begin{array}{l}\text { Wind Speed } \\
3 \mathrm{~m} / \mathrm{s}\end{array}$} & \multicolumn{3}{|c|}{$\begin{array}{l}\text { Wind Speed } \\
\qquad 5 \mathrm{~m} / \mathrm{s}\end{array}$} & \multicolumn{3}{|c|}{$\begin{array}{c}\text { Wind Speed } \\
10 \mathrm{~m} / \mathrm{s}\end{array}$} \\
\hline & 5 & 10 & 30 & 5 & 10 & 30 & 5 & 10 & 30 \\
\hline $\mathbf{A}$ & 0.48 & 0. & 0 & 0.76 & 0. & 0.70 & 1.60 & 1.53 & 1.43 \\
\hline B & 0.41 & 0.40 & 0.39 & 0.70 & 0.68 & 0.64 & 1.42 & 1.40 & 1.33 \\
\hline C & 0.34 & 0.34 & 0.33 & 0.60 & 0.59 & 0.57 & 1.32 & 1.27 & 1.20 \\
\hline D & 0.30 & 0.30 & 0.30 & 0.55 & 0.55 & 0.54 & 1.26 & 1.22 & 1.16 \\
\hline $\mathbf{E}$ & 0.21 & 0.22 & 0.23 & 0.45 & 0.45 & 0.45 & 1.11 & 1.08 & 1.03 \\
\hline $\mathbf{F}$ & 0.15 & 0.16 & 0. & 0.32 & 0.33 & 0.34 & 0.91 & 0.90 & 0.88 \\
\hline G & 0.28 & 0.28 & 0.29 & 0.50 & 0.50 & 0.50 & 1.09 & 1.07 & 1.04 \\
\hline H & 0.33 & 0.33 & 0.33 & 0.54 & 0.54 & 0.54 & 1.17 & 1.15 & 1.11 \\
\hline I & 0.40 & 0.39 & 0.37 & 0.64 & 0.63 & 0.61 & 1.30 & 1.26 & 1.20 \\
\hline
\end{tabular}
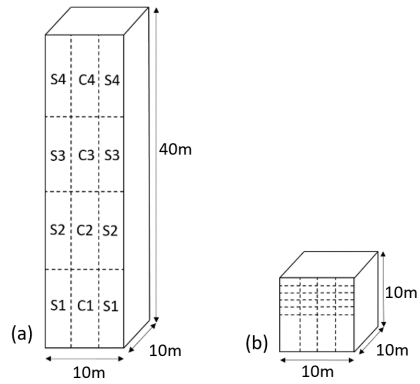

Figure 2: Models' geometric parameters.

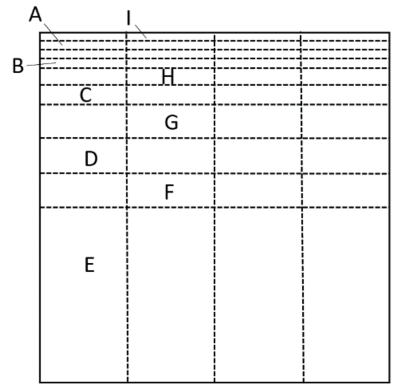

Figure 3: Facade sections of HAMFEM.

\section{ISO Standard and S\&B model}

As ISO Standard and S\&B semi-empirical models are the most common sources of WDR data. The two calculation models are applied to the high-rise and cubic reference buildings. In the ISO model, $C_{R}$ is calculated based on equations 4 and 5 below, and terrain category $I$, with $K_{R}=0.17, z_{0}=0.01$ and $z_{\min }=2$.

$$
\begin{gathered}
C_{R}(z)=K_{R} \ln \left(\frac{z}{z_{0}}\right) \text { for } z \geq z_{\text {min }} \\
C_{R}(z)=C_{R}\left(z_{\text {min }}\right) \text { for } z<z_{\text {min }}
\end{gathered}
$$

$C_{T}$ and $O$, based on this case, are both considered to be 1 based on tables in Blocken and Carmeliet (2010). The wall factor $W$ is chosen based on the information in the Standard depending on the building size, shape and height of point of interest with values of $0.2,0.3,0.4$ and 0.5 .

For the S\&B model, the RAF data provided for facades only includes aspect ratios of $H \gg W$, or $W \gg H$. Strictly speaking, the S\&B model cannot be applied for the cubic model Figure 2(b) but because this model is applied in practice for cubic buildings, it will also be applied here. For this work, $W \gg H$ is used for the cubic model and RAF data used for both models are 0, 0.5, 0.8 and 1 .

Figure 4 shows the catch ratios on the windward facades of the two building models estimated by the semi-empirical models and compares them to the referenced data produced by CFD for three $R_{h}$ values.

\section{ANNs for WDR catch ratio}

The modelling of the neural networks for this work has been done using the statistical package $\mathrm{R}$ and the 'neuralnet' package (Fritsch et al. (2016)). The neural networks in this package are feed-forward trained and focuses on multi-layer perceptrons (MLP) (Günther and Fritsch (2010)). MLP is a neural network with input and output layers and one or more hidden layers between them. The training and validation data was randomly separated by $\mathrm{R}$ to $80 \%$ and $20 \%$ respectively. Five input parameters were used for the creation of the neural network: the $\mathrm{x}$ coordinate, the $y$ coordinate of the point on building's façade, the aspect ratio of the façade, wind speed and horizontal rain intensity.

Several configurations of ANN were investigated to define the best number of hidden layers and neurons in each layer with the chosen one shown in Figure 5. The log sigmoid function as shown in equation 6 , has been used in all configurations of the ANN to ensure that the output signal of each node is smooth and as stated by Duch and Jankowski (1999) and Widrow and Lehr (1990) is the most appropriate for this application

$$
s(x)=1 /\left(1+e^{-x}\right)
$$

Where $\mathrm{x}$ corresponds to the sum of the weighted input of each previous node plus the bias of the node itself.

The input and output data of the ANN were normalised within the same boundaries as the 

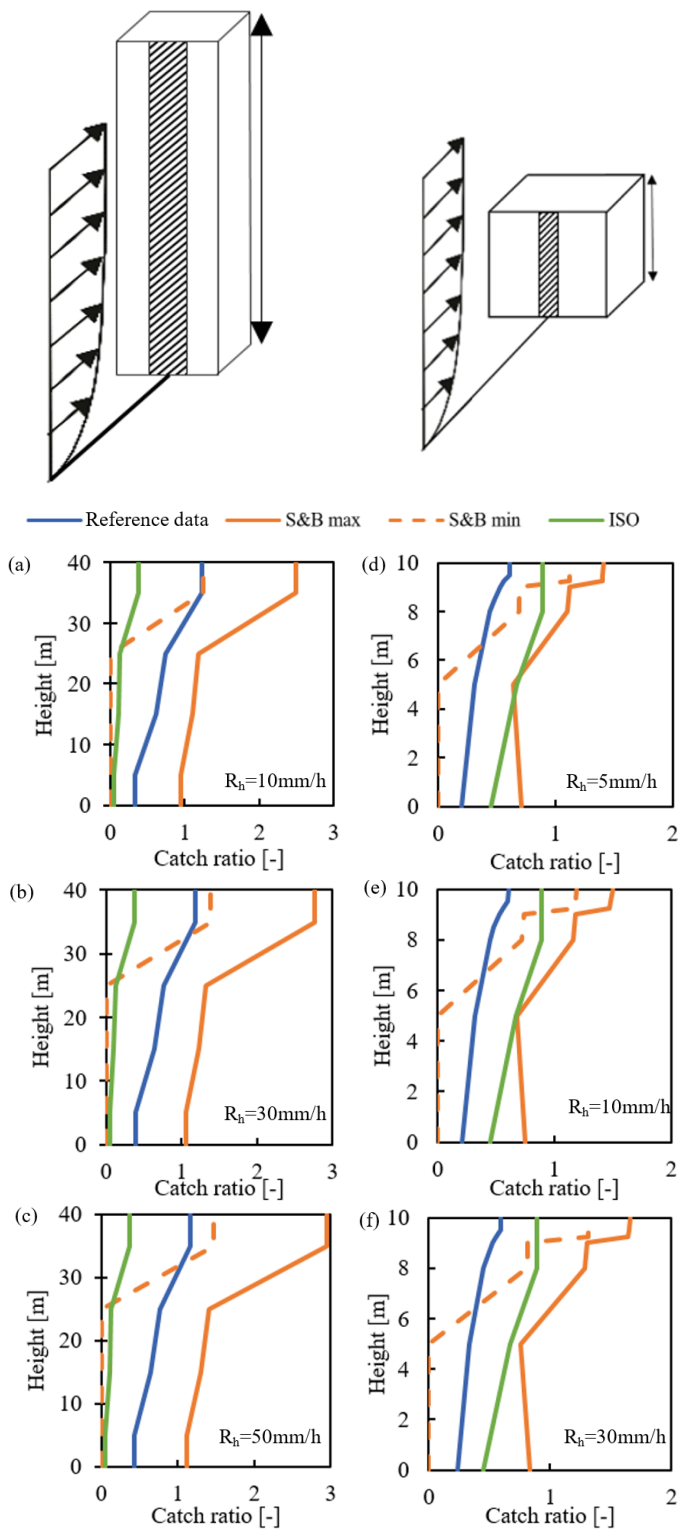

Figure 4: Comparison of wind-driven rain catch ratios for the two datasets, as obtained by three models (reference data, ISO, S\&B) for three different horizontal rainfall intensities.

activation function which is the sigmoid function in this case between 0 and 1 (Guoqiang Zhang et al. (1998)). Validation is a critical aspect of any model construction and therefore only the validation results were included in the graphs of ANN predictions compared to HAMFEM database values. The comparison between the HAMFEM WDR catch ratio values data and the ANN results was analysed based on the RMSE, which was used to calculate confidence intervals based on the same criterion and assumptions listed in the previous section. The frequency of errors between the HAMFEM database and the neural network results was also analysed using histograms.

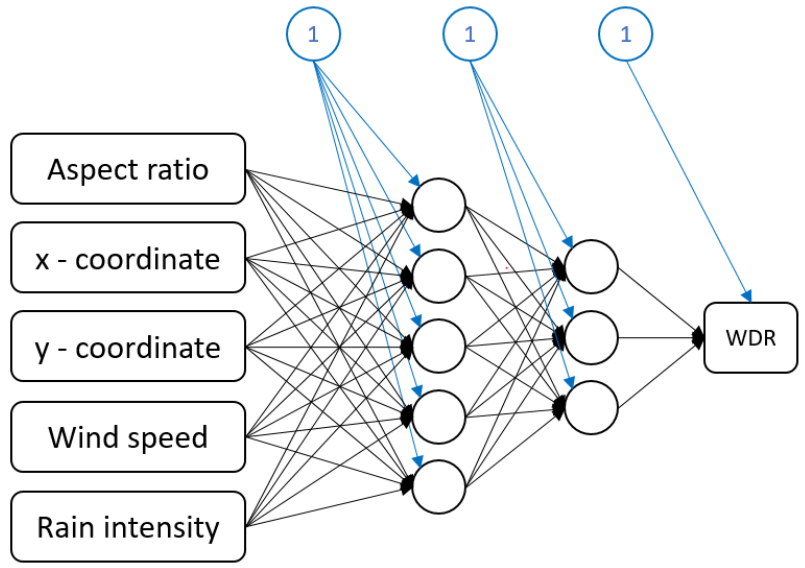

Figure 5: Artificial Neural Network Layout.

\section{Results and Discussion}

Figures 6 and 7 show a comparison for each data entry between the reference data and the two existing data sources of WDR catch ratio used in building simulations. These figures show symmetry plots where reference data is on $\mathrm{x}$-axis and the ISO and $\mathrm{S} \& \mathrm{~B}$ data on $\mathrm{y}$-axis. In both cases, the state of the art data fails to capture the complexity of WDR catch ratio distribution in the models. This can be better quantified through the histograms in Figure 8 which show the frequency of errors. Errors are comparable for both data sources and vary from -0.37 to +1.87 , which is on similar order of magnitude of WDR catch ratio data (varies from 0 to +2.3 in this dataset). Assuming a normal distribution of errors, the calculated confidence intervals of ISO and S\&B data are \pm 0.56 and \pm 1.03 respectively for a confidence level of $95 \%$. Due to the fact that $\mathrm{S} \& \mathrm{~B}$ model provides maximum and minimum RAF values, for comparison purposes the average value between the two is used in this case.

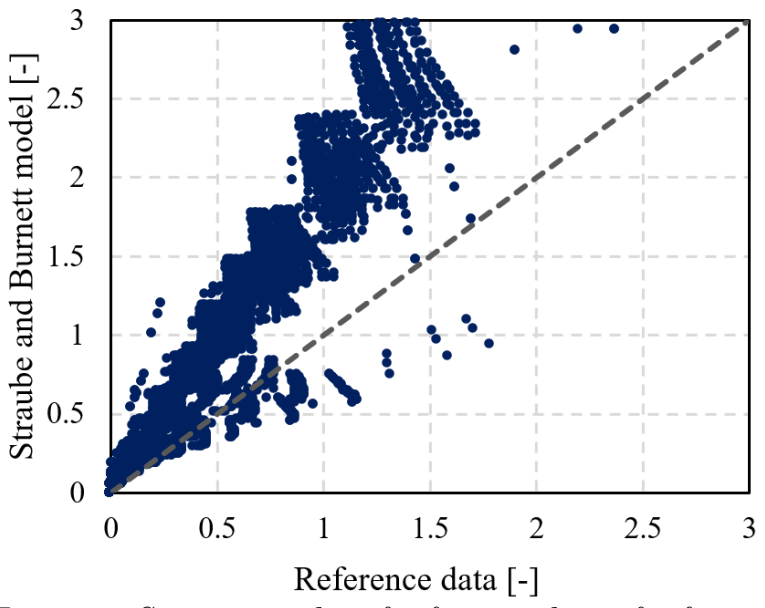

Figure 6: Symmetry plot of reference data of reference data compared to Straube and Burnett model.

Results in Figure ?? show the comparison between the ANN predictions for the validation data and the WDR data from the reference data. ANN results have 
good agreement, particularly in comparison to data in Figures 6 and 7 (which represent the best practice in terms of WDR data using semi-empirical sources). The best setting for the ANN comprises two hidden layers with 5 and 3 nodes respectively (Figure 5 ). The frequency of errors (calculated based on the method outlined earlier) is shown in Figure 10. Predictions using this set of ANN have a confidence interval of $\pm 0.07(\mathrm{RMSE}=0.036)$ for a confidence level of $95 \%$. Table ?? includes all the weights and biases extracted from the trained ANN which shows the effect of wind speed and horizontal rainfall intensity on the ANN output. The closer to 0 the weights are the less or no effect they have on the WDR catch-ratios.

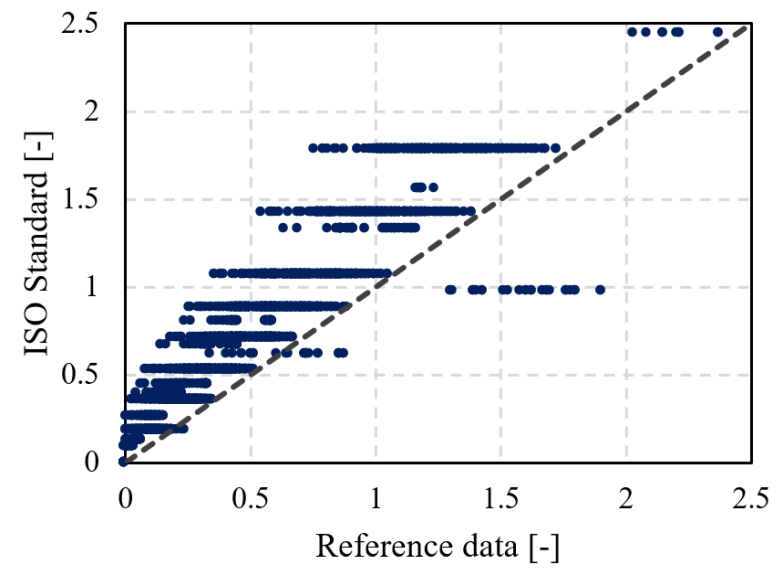

Figure 7: Symmetry plot of reference data of reference data compared to ISO Standard model.

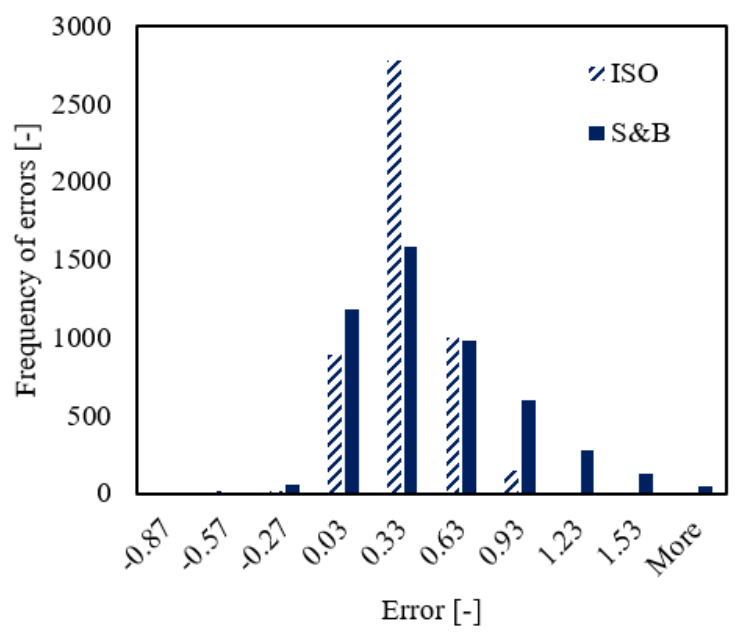

Figure 8: Histogram of errors in WDR catch ratio calculations for ISO Standard and S\&B model.

\section{Conclusions}

This work described the development of artificial neural networks for the prediction of wind-driven rain catch-ratios. As main objective of this work, is the use of machine learning in building simulation which in this case is wind-driven rain catch-ratios. The conclusions drawn based on the results presented are:

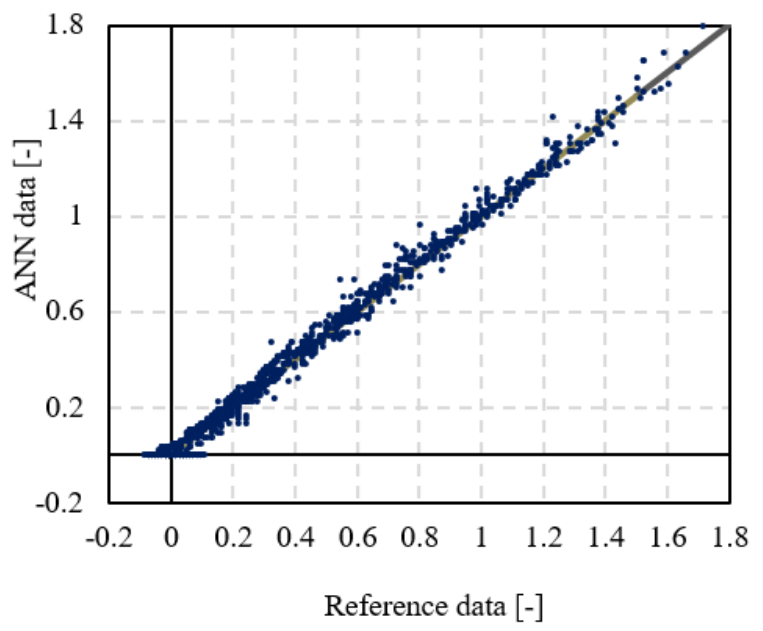

Figure 9: Symmetry plot of reference data of reference data compared to $A N N$.

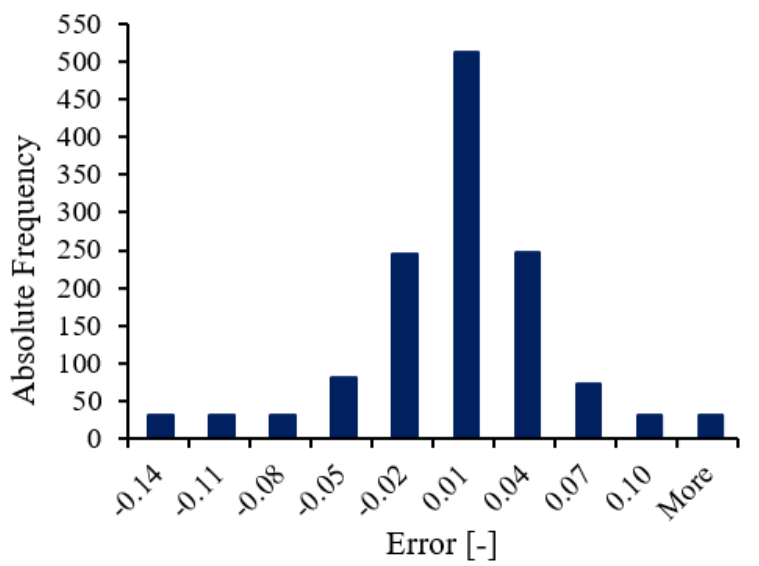

Figure 10: Histogram of errors in ANN calculations of reference data from $C F D$ and HAMFEM compared to $A N N$.

- The trained and tested artificial neural networks using the reference data from CFD simulations and Heat Air Moisture Finite Element Method program showed that wind-driven rain catch ratios can be predicted with \pm 0.07 confidence interval for a confidence level of $95 \%$.

- One artificial neural network per wind speed or horizontal rainfall intensity could possibly be considered for further work as weights and biases indicate their effect on the results.

- A neural network with 2 hidden layers with 5 and 3 nodes respectively showed the best results when compared to other ANN configurations. 
Table 3: Weights and biases of the ANN.

\begin{tabular}{|c|c|c|c|c|c|c|c|c|c|c|c|c|c|}
\hline & \multicolumn{10}{|c|}{ Weights } & \multirow[t]{3}{*}{ Bias 1} & \multirow[t]{3}{*}{ Bias 2} & \multirow{2}{*}{$\begin{array}{c}\text { Weight } \\
\text { Output } \\
\text { WDR }\end{array}$} \\
\hline & \multicolumn{2}{|c|}{ Aspect ratio } & \multicolumn{2}{|c|}{$\mathrm{x}$-coordinate } & \multicolumn{2}{|c|}{$\mathrm{y}$-coordinate } & \multicolumn{2}{|c|}{ Wind speed } & \multicolumn{2}{|c|}{ Horizontal Intensity } & & & \\
\hline Neurons & Layer 1 & Layer 2 & Layer 1 & Layer 2 & Layer 1 & Layer 2 & Layer 1 & Layer 2 & Layer 1 & Layer 2 & & & \\
\hline 1 & 5.838 & -4.402 & -33.958 & -4.260 & -158.407 & -5.731 & 82.245 & -14.235 & 0.179 & -40.920 & -8.496 & 7.913 & -0.768 \\
\hline 2 & -2.112 & -2.38 & 4.858 & 2.892 & 1.682 & 1.678 & 2.492 & 9.704 & -0.406 & -3.670 & -7.218 & 3.097 & -1.388 \\
\hline 3 & 0.159 & -3.051 & -0.012 & 3.472 & -0.236 & -0.864 & -1.282 & 12.066 & 338.415 & 0.926 & -1.443 & -0.769 & 0.973 \\
\hline 4 & -3.232 & & -1.020 & & 3.328 & & 2.013 & & -0.299 & & -3.330 & & \\
\hline 5 & -0.406 & & 0.035 & & 0.712 & & 1.988 & & 0.140 & & -0.181 & & \\
\hline WDR & & & & & & & & & & & & 0.573 & \\
\hline
\end{tabular}

\section{Acknowledgment}

This research is funded by the University of Strathclyde and BRE Trust. Their financial contribution is greatly acknowledged.

\section{References}

Abuku, M., B. Blocken, and S. Roels (2009). Moisture response of building facades to wind-driven rain: Field measurements compared with numerical simulations. Journal of Wind Engineering and Industrial Aerodynamics 97(5-6), 197-207.

Amasyali, K. and N. M. El-gohary (2018). A review of data-driven building energy consumption prediction studies. Renewable and Sustainable Energy Reviews 81 (April 2017), 1192-1205.

Aram, Z., S. Jafari, J. Ma, J. C. Sprott, S. Zendehrouh, and V. T. Pham (2017). Using chaotic artificial neural networks to model memory in the brain. Communications in Nonlinear Science and Numerical Simulation 44, 449-459.

Best, A. C. (1950). The size distribution of raindrops. Quarterly Journal of the Royal Meteorological Society 76(327), 16-36.

Blocken, B. and J. Carmeliet (2002, oct). Spatial and temporal distribution of driving rain on a low-rise building, Volume 5.

Blocken, B. and J. Carmeliet (2004). A review of wind-driven rain research in building science. Journal of Wind Engineering and Industrial Aerodynamics 92(13), 1079-1130.

Blocken, B. and J. Carmeliet (2007). On the errors associated with the use of hourly data in wind-driven rain calculations on building facades. Atmospheric Environment 41(11), 2335-2343.

Blocken, B. and J. Carmeliet (2010). Overview of three state-of-the-art wind-driven rain assessment models and comparison based on model theory. Building and Environment 45(3), 691-703.

Blocken, B., S. Roels, and J. Carmeliet (2007). A combined CFD-HAM approach for wind-driven rain on building facades. Journal of Wind Engineering and Industrial Aerodynamics 95(7), 585607.
Choi, E. C. C. (1993, jan). Simulation of wind-drivenrain around a building. Computational Wind Engineering 1, 721-729.

Choi, E. C. C. (1994). Determination of wind-drivenrain intensity on building faces. Journal of Wind Engineering and Industrial Aerodynamics 51(1), 55-69.

Deb, C., L. S. Eang, J. Yang, and M. Santamouris (2016). Forecasting diurnal cooling energy load for institutional buildings using Artificial Neural Networks. Energy and Buildings 121, 284-297.

Duch, W. and N. Jankowski (1999). Survey of neural transfer functions. Neural Computing Surveys 2, 163-212.

Elnesr, M. and A. Alazba (2017). Simulation of water distribution under surface dripper using artificial neural networks. Computers and Electronics in Agriculture 143(October), 90-99.

Fritsch, S., F. Guenther, M. Suling, and S. M. Mueller (2016). Training of neural networks. Package 'neuralnet'. The $\mathrm{R}$ project for statistical computing. pp. 13.

Günther, F. and S. Fritsch (2010). neuralnet: Training of Neural Networks. The R Journal 2(1), 3038.

Guoqiang Zhang, B. Eddy Patuwo, and Michael Y. $\mathrm{Hu}$ (1998). Forecasting with artificial neural networks: The state of the art. International Journal of Forecasting 14, 35-62.

ISO (2009). Hygrothermal performance of buildings - calculation and presentation of climatic data Part 3: calculation of a driving rain index for vertical surfaces from hourly wind and rain data.e. International Organization for Standardization (ISO 2009;15927-3).

Janssen, H. (2000). HAMFEM Manual 1 / 2 / 3-D Simulation Model for Heat-Air-Moisture Transfer in Building Components. pp. 1-9.

Khera, N. and S. A. Khan (2017). Prognostics of aluminum electrolytic capacitors using artificial neural network approach. Microelectronics Reliability (October), 0-1. 
Kumar, R., R. K. Aggarwal, and J. D. Sharma (2013). Energy analysis of a building using artificial neural network: A review. Energy and Buildings 65, 352358.

Magalhães, S. M., V. M. Leal, and I. M. Horta (2017). Modelling the relationship between heating energy use and indoor temperatures in residential buildings through Artificial Neural Networks considering occupant behavior. Energy and Buildings 151, 332-343.

Melo, A. P., D. Cóstola, R. Lamberts, and J. L. M. Hensen (2014). Development of surrogate models using artificial neural network for building shell energy labelling. Energy Policy 69, 457-466.

Seyedashraf, O., A. Rezaei, and A. A. Akhtari (2017). Dam break flow solution using artificial neural network. Ocean Engineering 142(June 2016), 125132.

Straube, J. and E. Burnett (2000). Simplified prediction of driving rain deposition. Proceedings of the international Building Physiscs Conference (February), 375-382.

Tavana, M., A.-R. Abtahi, D. Di Caprio, and M. Poortarigh (2017). An Artificial Neural Network and Bayesian Network model for liquidity risk assessment in banking. Neurocomputing 275, 25252554 .

von Grabe, J. (2016). Potential of artificial neural networks to predict thermal sensation votes. $A p$ plied Energy 161, 412-424.

Vrachimi, I., A. P. Melo, and D. Cóstola (2017). Prediction of wind pressure coefficients in building energy simulation using machine learning. Proceedings of International Building Performance Simulation Association Conference (September), 23342341.

Widrow, B. and M. A. Lehr (1990). 30 Years of Adaptive Neural Networks: Perceptron, Madaline, and Backpropagation. Proceedings of the IEEE 78(9), 1415-1442. 